Divers@ Revista Eletrônica Interdisciplinar, Matinhos, v. 8, n. 2, p. 132-144, jul./dez. 2015

\title{
CONSERVADORISMO E REVOLUÇÃO (OU REFORMISMO) NA BIBLIOTECONOMIA E NA CIÊNCIA DA INFORMAÇÃO
}

\author{
CONSERVATISM AND REVOLUCION (OR REFORMISM) IN LIBRARY SCIENCE AND \\ INFORMATION SCIENCE
}

Oswaldo Francisco de Almeida Júnior ${ }^{1}$

\begin{abstract}
Resumo
A Biblioteconomia e a Ciência da Informação, historicamente, flertam com o conservadorismo, embora tal postura não seja apresentada de forma explícita. Todas as iniciativas, tanto no âmbito dos que atuam diretamente no mercado ou no âmbito acadêmico, que tentaram trazer para discussão ideias opostas a essa, ou seja, relacionadas a pontos de vista mais progressistas, lutaram contra propostas que visavam ou inibir o desenvolvimento dessas ideias ou apresentar concepções amenizadoras das defesas presentes naquelas iniciativas. Alguns momentos históricos podem servir de exemplo para embasar as afirmações apresentadas durante o texto. Termos como "Informação Social" e "Biblioteca Popular" e as concepções presentes na Mediação da Informação sofreram oposição oriunda, principalmente, do meio acadêmico. Ampliar as discussões, os debates, os estudos e as pesquisas, apresenta-se como primordial para manter o tema entre as preocupações da área. Além disso, as concepções presentes nos temários mais progressistas devem ser vistas como resistência no próprio âmago da Biblioteconomia e da Ciência da Informação.
\end{abstract}

Palavras-chave: biblioteconomia; ciência da informação; conservadorismo; mediação da informação.

Artigo Científico: Recebido em 23/10/2015 - Aprovado em 05/01/2016

${ }^{1}$ Doutor e Mestre em Ciências da Comunicação pela ECA/USP; Professor Associado da Universidade Estadual de Londrina e Professor permanente do Programa de Pós-Graduação em Ciência da Informação da UNESP/Marília. E-mail: ofaj@ofaj.com.br (autor correspondente) 


\begin{abstract}
The Library and Information Science, historically, flirt with conservatism, although this approach is not presented in an explicit way. All the initiatives as far in the context of which act directly in the market or in the academic, who have tried to bring the discussion opposing ideas of this, that is, related to most progressive views, fought against proposals aimed at or inhibit the development of these ideas or present milder conceptions from the defenses present in those initiatives. Some historical moments can serve as an example on which to base the assertions presented in the text. Terms such as "Social Information" and "Popular Library" and the conceptions present in the Information Mediation suffered opposition arising from mainly academic circles. Broaden discussions, debates, studies and research, is presented as essential to keep the theme of area concerns. In addition, the views present in most progressive themes must be seen as resistance at the very center of Library Science and Information Science.
\end{abstract}

Keywords: library science; information science; conservatism; mediation of information.

\section{Introdução}

A Biblioteconomia e a Ciência da informação flertam, ambas, com o conservadorismo. Mais do que flertam, namoram e se casam com o conservadorismo. Historicamente, tanto uma como outra atrelaram seus interesses e fazeres a concepções que repudiam o novo, que repudiam as propostas de mudanças. Quando as aceitam, o fazem de maneira a alterar apenas o superficial, em uma aparente transformação, embora o cerne, o âmago permaneça o mesmo.

Desde seus primórdios, a Biblioteconomia conserva o conhecimento dos dominantes. A história que permanece nos registros oficiais é a dos que venceram, tanto as batalhas físicas, travadas em campos abertos e lutas corporais, como os embates de ideias, de interesses, de conceitos. Luta-se tanto no âmbito concreto como no ideológico, no simbólico, no imaginário.

Os acervos das bibliotecas mantiveram e mantém o registro oficial da história. Do mesmo modo, conserva um entendimento hegemônico de mundo, aquele voltado aos interesses das classes dominantes. Preservam não só esse olhar histórico, como também a gramática imposta por uma elite de acadêmicos alçados à condição de determinadores da língua culta, da norma padrão. O sistema de dominação impõe a eleição tácita dessas instâncias que contribuem para que o mesmo permaneça. A língua, dentro da forma apresentada e assimilada como correta, é uma das armas do conservadorismo.

O conhecimento preservado pelas bibliotecas, assim, é o conhecimento das elites, o conhecimento dos dominadores, o conhecimento dos excludentes. O que não significa, evidentemente, que as classes populares não construam conhecimento. Preserva-se e conserva-se aquele conhecimento defendido como único, ou como vinculado à verdade. A ciência produz um conhecimento que deve ser entendido como o conhecimento verdadeiro. $\mathrm{O}$ conhecimento popular é, nessa visão, um mero saber, estruturado apenas em uma relação empírica com o mundo, desprovido do teórico que, em última instância, por atrelar-se ao racional, é o que dá credibilidade, cientificidade e veracidade ao conhecimento.

De maneira semelhante, o discurso válido é o pronunciado e enunciado por pessoas a quem o sistema outorga uma competência para isso. No entanto, tal competência pode não estar relacionada aos conhecimentos específicos dessas pessoas sobre o tema, mas em atributos periféricos, que circundam e margeiam esses conhecimentos.

As reflexões e discussões de Marilena Chauí sobre a relação tecnologia e ciência no âmbito da dominação política, econômica, cultural, entre outras, devem ser apresentadas aqui, de maneira sucinta e a partir de uma citação, para servir de fundamento a afirmações que faremos posteriormente.

[...] desde o século XVII até meados do século XX (mais exatamente, até o final da Segunda Guerra Mundial), julgava-se que as ciências eram teorias puras que, na prática, podiam tornar-se ciências aplicadas por meio das técnicas, a maioria das quais era empregada pela economia capitalista para a acumulação e reprodução 
do capital. O caso mais visível desse uso de conhecimentos científicos era seu emprego na construção de máquinas para o processo de trabalho. Hoje, porém, não se trata mais de usar técnicas vindas de aplicação prática das ciências, e sim de usar e desenvolver tecnologias. A tecnologia surge desde o século XVII, com a fabricação de instrumentos de precisão que pressupõem conhecimentos científicos para serem produzidos e que, uma vez construídos, interferem no próprio conteúdo das ciências [...]. Em outras palavras, a tecnologia é resultado de conhecimentos científicos [...] e, ao mesmo tempo, condição para o avanço desses conhecimentos. A transformação da técnica em tecnologia e a absorção das ciências pelas tecnologias levou ao que hoje chamamos de tecnociência. (CHAUÍ, 2014, p.55-56).

Outro autor que podemos trazer para ampliar esta discussão é Jessé Souza. Abordando aspectos da ciência e dos intelectuais, afirma:

É preciso levar em conta que, na sociedade contemporânea, a legitimação da dominação social é realizada pela "ciência" de modo semelhante à maneira como as grandes religiões do passado faziam nas sociedades tradicionais. São sempre ideias de intelectuais e especialistas que estão na base de programas de partido político, de planejamento do Estado, do que se ensina em salas de aula, do que se decide em tribunais e daquilo que se publica em jornais. (SOUZA, 2015, p.12).

Diz ainda que "a dominação social material e concreta de todos os dias só é efetiva e tende a se eternizar se é capaz de se 'justificar' e convencer. E produzir 'convencimento' é precisamente o trabalho dos intelectuais do mundo moderno, substituindo os padres e religiosos do passado" (SOUZA, 2015, p.12).

A respeito do Brasil, o autor entende que "[...] tamanha 'violência simbólica' só é possível pelo sequestro da 'inteligência brasileira' para o serviço não da imensa maioria da população, mas do $1 \%$ mais rico, que monopoliza a parte do leão dos bens e recursos escassos" (SOUZA, 2015, p.10).
Vale reproduzir outro pequeno trecho do livro desse autor: "[...] a 'ciência' - e os cientistas e especialista que a incorporam - é, atualmente, quem herda o 'prestígio' das grandes religiões do passado e diz o que é certo e o que é errado. Não existe notícia em jornal ou TV que não necessite do 'aval' de um especialista" (SOUZA, 2015, p.11).

Marilena Chauí, em seu texto "O discurso competente" trabalha com a conceituação desse discurso (CHAUÍ, 2006).

As bases técnicas da Biblioteconomia e tecnológica da Ciência da Informação (esta última denominada de ciência, pois tecnologia e ciência se auto alimentam e buscam nessa relação uma legitimação por parte da sociedade) podem ser claramente observadas e relacionadas com as posições apresentadas por Marilena Chauí (2006; 2014) e Jessé Souza (2015).

\section{Biblioteconomia}

Os acervos das bibliotecas, como dizíamos, resgatam e conservam um conhecimento específico. Cada acervo se constitui em um discurso único e diferenciado. No entanto, a base fundante desses discursos é a mesma. Poucas são as bibliotecas que constroem seus acervos a partir de uma política de desenvolvimento de coleções baseada na linguagem popular, na produção de materiais por parte da comunidade atendida por essas bibliotecas, nos interesses e necessidades dessa comunidade. Ao contrário, os bibliotecários se atêm a aplicação de políticas já testadas e utilizadas em outros equipamentos informacionais, com pouca ou nenhuma adequação.

As bibliotecas, por preservarem e veicularem o conhecimento dos dominantes, impedindo que o conhecimento das classes populares seja conhecido, caminharam pari passu com as elites. Também por esse motivo, foram e ainda são sustentadas e mantidas por elas.

Ortega y Gasset (2006) observou que uma profissão permanece ativa até que a sociedade a considere desnecessária. Essa situação já ocorreu com várias profissões. As bibliotecas de há muito são consideradas como "elefantes brancos", espaços que para pouco servem, entre outras. Os próprios bibliotecários afirmam em textos, eventos ou em 
conversas informais com colegas de profissão, que o seu fazer, apesar de importante e possuir uma função social inequívoca, não é compreendido pela sociedade. Esta não entende o fazer bibliotecário, não compreende a importância do trabalho dos bibliotecários, não consegue perceber como a biblioteca pode contribuir com o desenvolvimento e ampliação de seu conhecimento. A biblioteca e os bibliotecários são importantes, mas incompreendidos.

Diante disso, a pergunta que nos fazemos é por que uma profissão não reconhecida e entendida pela sociedade como um espaço pouco utilizado, cuja função não é entendida, continua existindo, contrariando o entendimento de que a sociedade a eliminaria?

Quando nos deparamos com tal questão, a única resposta plausível aponta para a sustentação, pelas classes dominantes - que controlam as instâncias de poder - tanto do espaço biblioteca, como dos profissionais que nela atuam. Essa sustentação dá-se uma vez que as bibliotecas e os bibliotecários preservam e mantêm os conhecimentos dessas classes. As bibliotecas, a partir dessa ótica, possuem uma importante função, identificada com os interesses das classes dominantes. A existência das bibliotecas está afeita a essa função, não importando que voltada apenas a um pequeno segmento da sociedade. Aliás, segmento que não se utiliza dos espaços da biblioteca.

A Biblioteconomia, como afirma Serrai (1975), tem sua história vinculada às técnicas bibliotecárias. Essa afirmação nos remete a uma concepção de Biblioteconomia dissociada da sociedade. Sua existência dá-se em seu próprio seio, amamentandose de técnicas e apresentando-se como organizadora do conhecimento humano e, a partir disso, afirma, possibilitando a recuperação de informações.

As técnicas devem visar o atendimento a demandas por informações, a buscas por informações, a recuperação de informações. Assim, a recuperação, ou a ideia de recuperação é anterior à de organização. Organiza-se porque há uma demanda originada por necessidades de informação, advindas da sociedade. $\mathrm{O}$ núcleo duro da área não pode ficar circunscrito unicamente na organização, como quer a concepção hegemônica da
Biblioteconomia; o núcleo duro deve se diluir em todos os segmentos da área.

Em resumo: há um pacto da Biblioteconomia com os excludentes, com os dominadores, visando a sobrevivência das bibliotecas, dos bibliotecários e do próprio campo de estudos, como afirma Almeida Júnior (2004). Do outro lado, a experiência da Biblioteconomia com a maioria da população dá-se pontualmente, em pequenas experiências, apresentando-se como resistência a uma situação aceita como detentora da verdade. Em sua história, a Biblioteconomia isolou-se da sociedade, encastelando-se em seu espaço, empregando técnicas criadas para atender e responder necessidades oriundas de suas próprias entranhas.

\section{Ciência da Informação}

A Ciência da Informação também possui uma concepção aceita pela maioria dos que a têm como preocupação. Essa concepção advoga uma Ciência da Informação voltada exclusivamente para informações científicas e tecnológicas, e empregando, necessariamente, tecnologias para trabalhar e lidar com as informações. Alicerçada em ideias expressadas por Vannevar Bush na década dos anos 1940, a Ciência da informação sob essa visão relega a informação pública do rol de seus interesses e preocupações.

Sobre a origem da Ciência da Informação, Carlos Alberto Ávila Araújo afirma que

Nesse processo de institucionalização, foise firmando, por um lado, a ideia de que a ciência da informação era uma ciência dedicada à informação em ciência e tecnologia. Igualmente importante, contudo, foi a preocupação de base dessas ações: não mais a necessidade de se ter a posse dos documentos, mas a prioridade dada à sua circulação, ao seu fluxo, e ao atendimento das necessidades dos cientistas em sua frente de trabalho (ARAÚJO, 2014, p.91).

Ainda sobre a origem da Ciência da Informação, o mesmo autor, dentro de um histórico maior, escreve que

A information science nasceu e se consolidou no contexto anglo-saxão e soviético entre as décadas de 1940 e 1960 , 
e daí se espalhou para diversas outras regiões do planeta. Importante nessa consolidação foi a publicação, em 1968, do artigo, hoje considerado clássico, de Harold Borko, intitulado Information Science: what is it?, apresentando uma definição exaustivamente repetida do que viria a ser a nova área. Embora a intenção original da área parecesse buscar um amplo entendimento do fenômeno informacional, essa information science acabou por se constituir também numa especialização, mais uma ao lado das outras existentes, buscando ser um campo de estudos em recuperação automatizada da informação no contexto de informação em ciência e tecnologia. Essa área acabou por dialogar bem com a parte tecnicista da biblioteconomia, constituindo um campo designado library and information science, mas com pouca interlocução com campos como a arquivologia e a museologia e mesmo com a parte mais cultural e humanística (bibliotecas públicas, escolares, etc.) da biblioteconomia (ARAÚJO, 2014, p.96).

As ideias de ciência envolvida com a tecnologia, formando a tecnociência; de estudo da informação como subsídio, base e estrutura da ciência; a "pouca interlocução com a parte mais cultural e humanística da Biblioteconomia", e a despreocupação com as demandas oriundas da maioria da população, apontam para uma área que, a exemplo da Biblioteconomia, vincula-se aos extratos dominantes da sociedade. Sob essa ótica, é possível visualizar o caráter conservador da concepção mais amplamente defendida, atualmente, da Ciência da informação.

Presta-se, a Ciência da Informação, desse modo, a servir como mais uma arma, entre tantas outras, de dominação.

Na história brasileira, especificamente, a Ciência da Informação começa a ser implantada no início dos anos 1970. Se pensarmos nas ideias de Borko (1968), é quase de maneira imediata à publicação do texto daquele autor, vindo a público, para recordar, em 1968.

Até 1976, possuíamos um instituto voltado para atendimentos de necessidades da área da documentação, o IBBD - Instituto Brasileiro de Bibliografia e Documentação. Naquela data, esse instituto passa por uma grande reformulação e tem seu nome alterado para IBICT - Instituto Brasileiro de Informação em Ciência e Tecnologia.

A origem do IBICT remonta ao início da década de 50, quando a Unesco sugeriu à Fundação Getúlio Vargas (FGV), que promovesse a criação, no Brasil, de um centro nacional de bibliografia. A ação da Unesco, à época, foi decisiva para o surgimento de instituições do gênero em diferentes países. A escolha inicial da FGV deveu-se ao fato de aquela instituição estar realizando importantes atividades na área de bibliografia e documentação.

Por essa época, estava sendo criado, também, o Conselho Nacional de Pesquisas (CNPq), que tinha, entre suas atribuições, "manter relação com instituições nacionais e estrangeiras para intercâmbio de documentação técnicocientífica". Por meio de proposta conjunta $\mathrm{CNPq} / \mathrm{FGV}$, foi criado, em 27 de fevereiro de 1954, pelo Decreto do presidente da República $\mathrm{n}^{\circ} 35.124$, o Instituto Brasileiro de Bibliografia e Documentação (IBBD), que passou a integrar a estrutura organizacional do CNPq.

Os anos 70 são marcados por uma reorganização das atividades de ciência e tecnologia no país. Registra-se a transformação do Conselho Nacional de Pesquisas em Conselho Nacional de Desenvolvimento Científico e Tecnológico, ampliando o seu poder, transformando-o em fundação, ligando-o à Secretaria do Planejamento e à Presidência da República. Da mesma maneira que o CNPq, o IBBD passa por uma transformação, inclusive com a mudança de nome para Instituto Brasileiro de Informação em Ciência e Tecnologia (IBICT), com a publicação da Resolução Executiva do CNPq n ${ }^{\circ}$ 20/76. O IBICT consolidava-se, então, como órgão que coordenaria, no Brasil, as atividades de informação em C\&T." (INSTITUTO, [s.d.]).

Anteriormente, em 1970, foi criado o primeiro curso de pós-graduação stricto sensu, mestrado, na área de Ciência da Informação no Brasil

O Programa tem origem no Curso de Documentação Científica - CDC, criado pelo IBICT em 1955, em nível de 
especialização, que foi oferecido por cerca de 35 anos ininterruptamente. Em 1970, o IBICT deu início ao curso de mestrado em Ciência na Informação, pioneiro na introdução desse campo do conhecimento no Brasil e na América Latina. (PROGRAMA, [s.d.])

Importante notar que as citações ao IBICT presentes no trecho, referem-se, de fato, ao IBBD, órgão existente na época. Como afirmado no site, esse é o primeiro curso de pós-graduação criado no Brasil para a área de Ciência da Informação e, salvo engano, para a área de Biblioteconomia e de Documentação.

Fica claro nesse pequeno histórico, a mudança de foco dos interesses das instituições da época, em relação ao tipo de informação trabalhado. Uma ideia mais ampla, representada pelas denominações, tanto do IBBD, como do $\mathrm{CNPq}$ passa a se restringir à informação científica e tecnológica, presente nos termos designativos daquelas instituições - que tiveram seus nomes alterados - e, acrescentaríamos, a concepção de Ciência da Informação presente no primeiro Programa de pós-graduação.

Devemos lembrar também que o período de transformação e mudanças dessas instituições está vinculado ao da ditadura militar. Os interesses desta passavam longe do apoio a informações de caráter público, sobre as quais, certamente, os militares não teriam controle nos moldes a que estavam acostumados e desejavam. A concepção de desenvolvimento, passível de controle e cujo direcionamento pudesse ser determinado, e acompanhando as diretrizes da Ideologia da Segurança Nacional, caracteriza a prioridade dos investimentos do governo na ciência e tecnologia. Como vimos, são estas formas atuais de dominação e controle.

A ênfase nas informações científicas e tecnológicas implica em relegar a um plano inferior as informações públicas, as informações sociais.

Um texto clássico de Aldo Barreto (1994) permite visualizar a oferta de informações para as necessidades básicas das pessoas e a oferta de informações científicas e tecnológicas, de baixa demanda pela maioria da população (Figura 1).

Para as necessidades básicas, que representam na imagem a base inferior da pirâmide das necessidades, são produzidas e disseminadas a menor quantidade de informações - como é visível na pirâmide ao contrário dos estoques de informação. A maior quantidade de informação é gerada e veiculada visando atender a menor quantidade de necessidades das pessoas. A inversão denota uma preocupação evidente com o atendimento de demandas relacionadas não com as necessidades básicas da população, traduzidas na própria sobrevivência dela, mas com informações que atendem interesses de um pequeno grupo da

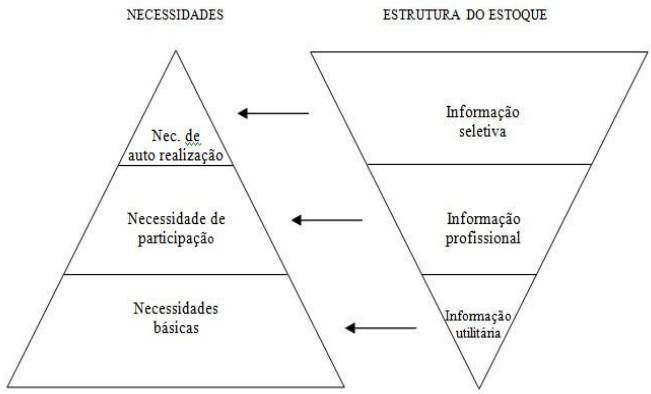

sociedade.

Figura 1. Necessidades humanas/Estoques informacionais Fonte: BARRETO (1994, p. 6)

$\mathrm{O}$ atendimento indireto das necessidades básicas, ou seja, as informações oferecidas para atender as demandas da ciência e tecnologia retornariam, de alguma forma, para a satisfação das necessidades básicas, poderia ser um argumento válido caso os investimentos nas pesquisas voltadas para tais necessidades fossem prioridades.

\section{Momentos}

Alguns momentos da história da Biblioteconomia e da Ciência da Informação podem servir de exemplos sobre o que discutimos até aqui. Nesses momentos, houve propostas e tentativas de estabelecer ideias contrárias às aceitas majoritariamente ou contrárias a concepções diferenciadas em relação às estabelecidas.

\subsection{Os termos Informação Utilitária e Biblioteca Comunitária}

Em uma clara contestação, acompanhando mudanças fortes ocorridas em boa parte da América Latina a partir, principalmente, de meados da década 
dos anos 1950, uma parcela da Biblioteconomia nesses locais, embora pequena, busca uma aproximação com os movimentos organizados da população.

Aqueles bibliotecários procuraram refletir a área a partir de parâmetros diferenciados dos que, até então, eram as bases para o entendimento dela. Tais novos parâmetros fizeram frente ao conservadorismo e à manutenção de um sistema que oprimia as classes populares. Estas, por sua vez, passaram a se valer de bases teóricas que a têm como foco central e ressaltam seus interesses, desejos e necessidades.

Reflexões sobre o conceito de informação eram imprescindíveis para embasar e dar suporte para as discussões que ocorriam naqueles segmentos da área, em especial nas bibliotecas públicas. Acompanhando as propostas de um olhar da Biblioteconomia para as classes populares e trabalhadoras, surgiram alguns termos que foram apropriados por aqueles que encabeçavam pesquisas, estudos e ações diferenciadas: informação social, informação para a cidadania, bibliotecas populares, centros de documentação e informação popular e outros próximos a esses. Os conceitos presentes nesses termos carregavam uma ideologia identificada com os interesses, desejos e necessidades das classes populares, voltadas, na época, para a exigência de que esses interesses, desejos e necessidades fossem considerados quando da instituição de políticas públicas, quando da determinação de políticas econômicas, educacionais, culturais, entre outras.

Várias publicações, no âmbito da Biblioteconomia, foram geradas e veiculadas nas revistas especializadas. As defesas de uma Biblioteconomia progressista, contrapondo-se a uma visão conservadora da área, tiveram espaços e iniciaram a constituição de uma corrente teórica que se aproximava das ideias presentes nos Movimentos Organizados, da resistência, ou melhor, das resistências contra governos autoritários em vários países da América Latina, da Igreja progressista, da Teologia da Libertação, entre outras. Era uma Biblioteconomia voltada para o povo, que buscava dar a voz, dar a palavra às classes populares, às classes trabalhadoras. Dar a palavra significa abrir espaços para que os interesses, necessidades e desejos delas pudessem se fazer ouvir, pudessem ser exteriorizados, tivessem espaços para serem conhecidos e reconhecidos.

A força dessa corrente abriu espaços para as discussões de temáticas que faziam parte de suas preocupações até mesmo em grandes eventos da área. Um deles, o Congresso Brasileiro de Biblioteconomia e Documentação - CBBD - o maior evento não acadêmico da área da Biblioteconomia no Brasil, em sua edição de 1982, na cidade de João Pessoa, Paraíba, escolheu como tema central "Biblioteca e Educação Permanente". Dentro desse tema, os relativos à Informação Pública tiveram destaque. Entre os palestrantes, Paulo Freire, Victor Flusser e Luis Milanesi.

A reação da corrente hegemônica, conservadora, não foi de confronto aberto, de defesa de conceitos e posições apontando para entendimentos contrários aos defendidos pelas ideias emergentes. Novos termos surgiram, impostos por pesquisadores que dominavam a maior parte dos espaços acadêmicos e dos movimentos associativos. Tais termos buscavam amenizar os conceitos que embasavam os termos Informação Social, Informação para a Cidadania, Bibliotecas Populares. No lugar destes, surgiram: "Biblioteca Comunitária" e "Informação Utilitária". Não houve, de fato, um confronto; o que ocorreu foi o uso, pelas correntes conservadoras, dos espaços por elas dominados para impor seus conceitos e se apoderar, a partir de seus interesses, de uma proposta que se propunha diferenciadora.

Uma rápida análise dos novos termos nos permite verificar a busca por diminuir a força dos termos anteriores: "Biblioteca Comunitária", substituindo "Biblioteca Popular" e "Informação Utilitária" substituindo "Informação Social" ou "Informação para a Cidadania". Todas as bibliotecas servem a uma comunidade, logo, todas são bibliotecas comunitárias. Quando se utiliza "Biblioteca Comunitária" está-se referindo a toda e qualquer biblioteca, esvaziando o termo de qualquer conotação política presente em "Biblioteca Popular". O mesmo se dá com "Informação Utilitária". Por definição, toda informação é útil. Assim, o termo "Informação Utilitária" é adequado para qualquer informação e seu emprego também o esvazia de qualquer conotação política, econômica e social presente nos termos "Informação Social" e "Informação para a Cidadania". 
Infelizmente, a Biblioteconomia voltada para o povo perdeu o embate. Venceram: "Biblioteca Comunitária" e "Informação Utilitária", termos empregados até hoje. Os outros, praticamente desapareceram.

\subsection{Documentação Popular}

No mesmo período, uma outra ideia diferenciada, dirigida para atender interesses das classes populares surgiu: a Documentação Popular.

No seio da Biblioteconomia a ideia de "Documentação Popular" nunca prosperou. A discussão de seu conceito esteve restrita aos movimentos organizados da população que se preocupavam com a organização da informação. Vários Centros Populares de Documentação ou Centros Populares de Informação entenderam que controlar a organização da informação seria uma arma contra a dominação exercida pelas classes opressoras. Entendiam também que as bibliotecas estavam a serviço das classes dominantes, assim com suas regras, normas, ações, instrumentos e técnicas.

Poucos textos chegaram a ser publicados, a maioria como literatura cinzenta. As ideias da Documentação Popular não obtiveram ecos entre os pesquisadores da Biblioteconomia.

Um texto que buscou definir Documentação Popular foi elaborado pelo Centro de Documentação Uruguaio América Latina - CEDUAL, publicado pelo CELADEC (1981) - Comissão Evangélica Latino-americana de Educação Cristã e traduzido pelo Centro Pastoral Vergueiro - CPV. Mimeografado, o documento serviu como suporte pedagógico para cursos ministrados em vários espaços ligados às entidades citadas.

No texto, Documentação Popular é assim conceituada:

Diante de uma documentação que serve de instrumento do sistema capitalista, desorganizando e desmobilizando o povo, surge a necessidade de realizar uma documentação libertadora, que seja um instrumento da libertação popular, que ajude no processo de educação, proporcionando aos setores populares informação verdadeira e objetiva, que responda às suas necessidades e interesses, servindo assim para conscientizar e não para alienar. Uma documentação que tenha a intenção de iniciar o rompimento do monopólio da informação e do conhecimento mantido pelos setores dominantes, colocando a informação e o conhecimento a serviço dos explorados e oprimidos. (CELADEC, 1981, p. 3).

A documentação é apresentada no documento como um "instrumento do sistema capitalista, desorganizando e desmobiliando o povo". A partir dessa ótica, o povo precisa dela se apropriar, transformando-a em um "instrumento da libertação popular".

Essa concepção da documentação não prosperou, ao contrário, foi ela totalmente esquecida, relegada à mesma penumbra acadêmica em que se encontram outras tantas propostas diferenciadas, progressistas.

\subsection{Desintermediação}

Em meados dos anos da década de 1990, aproximadamente, surge, em especial no Brasil, um novo segmento de pesquisa e estudos: a mediação da informação. Em um primeiro momento, estava ela voltada apenas para os espaços dos equipamentos informacionais que atuavam diretamente com os usuários, com o público.

O Serviço de Referência e Informação sempre abrigou as ações desenvolvidas com o atendimento ao público nas Bibliotecas. No entanto, as primeiras propostas para um espaço específico nas bibliotecas para atendimento ao usuário surgem apenas no final do século XIX. Antes, a preocupação maior estava voltada para a organização dos documentos, trabalho baseado em técnicas, de grande importância para a recuperação da informação desejada e necessitada pelos usuários, mas que não deve ser vista como o núcleo duro da área, entendimento amplamente veiculado e defendido por pesquisadores e estudiosos tanto da Biblioteconomia como da Ciência da Informação.

Defender a organização da informação como o núcleo duro da área leva a considerar como normal a ausência de bibliotecários no serviço de referência e informação, no momento em que há uma relação visível, presencial - mesmo que a distância, pois o acesso ao sistema das bibliotecas, hoje, pode ser 
feito de equipamentos remotos -, face a face entre a biblioteca e o usuário. Muitos acreditam que não há necessidade de preparo, formação, nem mesmo de profissionais bibliotecários nos trabalhos desenvolvidos pelo serviço de referência e informação. Qualquer pessoa pode realizar essa tarefa.

Os que atuam nesse setor, assim como os que o pesquisam e estudam, creem, com toda razão em nosso entendimento, que há necessidade de um amplo conhecimento dos trabalhos e atividades de todos os segmentos da Biblioteconomia para lidar com as questões de referência.

O serviço de referência e informação nunca teve, de fato, bases teóricas que fundamentassem suas ações, atividades e concepções. Basicamente, as propostas existentes eram norteadas para estudos de metodologia de trabalho, ou seja, quais as etapas que devem ser trilhadas no atendimento a um usuário.

A falta de uma fundamentação levou a um vácuo teórico, existente ainda hoje, dificultando as pesquisas e discussões no âmbito do serviço de referência e informação. Cobrindo essa falta, iniciam-se concepções sobre mediação da informação. As bases conceituais dela são oriundas de outras áreas do conhecimento humano e perfilamse com concepções mais progressistas dessas outras áreas e da Biblioteconomia e da Ciência da Informação.

Com a mediação da informação, o usuário passa a ter um espaço mais relevante, sendo considerado, de fato, protagonista dos trabalhos, atividades $\mathrm{e}$ ações desenvolvidos nas bibliotecas.

Todas as vezes em que o usuário é realçado ou tem sua existência percebida, tal situação causa um desconforto teórico, causa conflitos nas pesquisas majoritariamente tradicionalistas e conservadoras. São comuns defesas incondicionais da transformação em dogmas de conceitos admitidos como consolidados, estruturados, sedimentados. Ao contrário, advogamos aqui a necessidade de pensarmos, de refletirmos, de discutirmos sobre esses conceitos. Essa deve ser uma obrigação de todo pesquisador. Não discutir o que há muito vem sendo considerado como determinado, não passível de questionamento significa manter um mesmo e antigo pensar, significa impedir o repensar da área, uma clara característica de pensamentos conservadores.

Como aconteceu em outras situações, o crescimento das preocupações da área com a mediação da informação gerou ações contrárias, antagônicas, mesmo que não de maneira explícita.

A ideia de desintermediação surge como uma forma de refutar as ideias presentes na mediação da informação. Defendem que, na era da informática, das redes eletrônicas, a mediação é desnecessária, obsoleta ou, de maneira mais enfática, não há espaço para ela. Valendo-se de buscadores eletrônicos, o pesquisador, curioso, usuário enfim, pode conseguir informações sem a interferência de outros, sem a mediação de profissionais. Lança-se ao extremo uma ideia repetida constantemente - e em nosso entender, mal compreendida - de que as pessoas precisam aprender a aprender. Sabendo aprender sozinha, a pessoa deixa de necessitar de intermediários.

Voltamos a aceitar a dicotomia entre Emissor e Receptor presente no modelo matemático de comunicação, esquecendo a "vida", o "ser", o "acervo de experiências" existentes no momento e anteriormente em cada um dos personagens presentes naquele modelo?

A informação não é algo natural, não surge por geração espontânea, ao contrário, é ela produzida e vai se construindo em todo o seu ciclo de vida, incorporando a cada momento novos significados que podem ser observáveis ou estarem camuflados, escondidos nas dobras de vários interesses.

O armazenamento das informações é produto de ações de escolhas, seleções. Por sua vez, os mecanismos de buscas de informações nas redes têm interesses comerciais, visam lucro e, ao contrário do que normalmente veiculam, varrem prioritariamente segmentos da web com os quais possuem parcerias ou que, de uma forma ou outra, contribuem para o aumento dos lucros. O capitalismo não se destaca por sua generosidade.

O Google, por exemplo, é objeto, já há tempos, de análises e questionamentos por parte de pesquisadores. Alguns, entre eles Silvio Mieli (2008), utilizam a expressão "Googlarização da realidade" e apontam perigos no monopólio dos buscadores de informação. Segundo esses autores, 
estamos nas mãos e submetidos aos interesses dos grandes grupos que controlam as "pesquisas" na internet. $O$ Google não é neutro, nem mesmo fornece informações, ele indica locais e sítios em que as informações podem ser encontradas e o faz oferecendo links apresentados de maneira a fazer crer ao usuário, mesmo que não declaradamente, que há uma ordenação hierárquica e de importância.

Há sim, uma interferência das redes na apropriação de informações, desfazendo a ideia de que é possível uma desintermediação. A mediação é intrínseca à própria informação e ao trabalho desenvolvido nas bibliotecas.

A ideia de desintermediação é mais uma das tentativas de eliminar ou amenizar a busca por uma Biblioteconomia com interesses sociais, a busca por uma Biblioteconomia que trabalhe com um conceito de informação crítica.

\subsection{A mediação da informação vista apenas a partir de seu âmbito prático}

O conceito de mediação da informação está centrado em três ideias principais: interferência, apropriação e conflito. Para Almeida Júnior, mediação da informação é

Toda ação de interferência - realizada em um processo, por um profissional da informação e na ambiência de equipamentos informacionais -, direta ou indireta; consciente ou inconsciente; singular ou plural; individual ou coletiva; visando a apropriação de informação que satisfaça, parcialmente e de maneira momentânea, uma necessidade informacional, gerando conflitos e novas necessidades informacionais (ALMEIDA JÚNIOR, p.25, 2015a).

A mediação da informação possui duas dimensões, sendo uma intrínseca ao fazer do profissional.

"A mediação nesse caso é inerente ao fazer. Ela está presente, independente da vontade do profissional. Esse profissional veicula ideias, conceitos, concepções, valores de maneira consciente e inconsciente. Nesta dimensão da mediação, o profissional pode controlar muito do que dissemina, do que veicula, mas há um componente inconsciente sobre o qual ele não possui controle (ALMEIDA JÚNIOR, 2015b).

A outra dimensão é assim apresentada por Almeida Júnior:

Por outro lado, quando organizamos serviços, estruturamos o atendimento, propomos ações de educação de usuários, etc., estamos dentro de outra dimensão da mediação da informação, mais clara, mais consciente (embora também tenha muito de inconsciente), mais palpável, um pouco mais controlável. Precisamos, talvez, denominar essas dimensões para que suas diferenças sejam evidenciadas. Esta segunda dimensão identifica-se com a disseminação da informação. No entanto, a ideia de mediação da informação é mais abrangente que a da disseminação, uma vez que esta nunca se interessou com a apropriação da informação, atendo-se ao acesso físico do documento pelo usuário. Assim, a disseminação da informação está mais relacionada com a transferência da informação do que com a mediação da informação (ALMEIDA JÚNIOR, 2015b).

A tentativa de excluir a dimensão intrínseca das discussões sobre mediação da informação também pode ser caracterizada como a procura por eliminar conteúdos que se indispõem com a hegemônica concepção conservadora da Biblioteconomia e da Ciência da Informação, uma vez que a concentração restrita apenas ao fazer do profissional, sem ampliar as atenções para a fundamentação teórica da mediação da informação implica em retornar ao mesmo vácuo teórico existente no serviço de referência e informação e que motivou o surgimento da mediação da informação.

\subsection{Além da mediação}

Recentemente, uma nova ideia começa a surgir, a que está sendo chamada de "Além da Mediação". O título pode nos levar a crer que há uma proximidade com as concepções de István Mészáros, pois o principal livro deste autor chama-se "Para além do capital” (2006) e outro é intitulado "A educação para além do capital" (2005), mas, para frustração de muitos, o "Além da Mediação" na área da 
Biblioteconomia e da Ciência da Informação baseiase em outras correntes de pensamento.

A mediação da informação tem suas bases conceituais em concepções que se localizam na margem esquerda do pensar biblioteconômico e da Ciência da Informação. Seu compromisso com as necessidades, desejos e interesses das classes populares fica talvez não de todo explícito, mas é percebido quando se conhece os conceitos de informação, conhecimento que advoga; quando se conhece a estranheza com que lida com os conceitos de Sociedade da Informação, Sociedade do Conhecimento ou Sociedade da Informação e do Conhecimento; quando se conhece o emprego do termo "apropriação da informação" e não de "uso da informação"; quando afirma que a informação não dirime dúvidas, não cobre lacunas cognitivas, mas gera conflitos $\mathrm{e}$ tais conflitos exigem novas informações, assim, a informação gera novas necessidades, desejos, interesses; quando nos deparamos com questionamentos feitos ao próprio objeto da Biblioteconomia e da Ciência da Informação; entre outras.

A ideia básica presente nas propostas de "Além da Mediação" não acompanham os entendimentos da mediação da informação, ao contrário, são opostos a ela. Defendem que a informação transferida ao usuário deve ser "efetiva", "eficiente", deve satisfazer integralmente suas necessidades. Em oposição ao conflito, acredita-se na possibilidade do atendimento efetivo de uma necessidade informacional. A ideia de "transferência de informação" é contestada pela mediação da informação, uma vez que tal concepção crê no transporte de um "pacote" de conhecimento de uma pessoa para outra, ideia embutida no conceito de transferência de informação. "Além da Mediação" também acredita que a necessidade informacional é passível de ser totalmente visualizada, totalmente entendida e delimitada. A mediação da informação não trabalha com essa possibilidade. Para a mediação da informação, as necessidades, desejos e interesses informacionais não são puros, como não são puros nenhuma necessidade, desejo ou interesse. Existem eles como mescla de imposições sociais, apelos pessoais advindos de situações de momentos e acervo individual de experiências sensoriais e experiências cognitivas, sempre frutos de relação entre o indivíduo e o contexto onde habita, frutos do diálogo da pessoa com a sociedade e com os outros.

A mediação da informação trabalha com a ideia de que o conhecimento é construído individualmente, mas sempre na relação. Dessa forma, tanto o indivíduo como a natureza e a sociedade interferem na construção, embora pessoal, do conhecimento. As concepções de "Além da Mediação" passam longe dessa ideia, uma vez que concebe a possibilidade de uma informação eficiente e eficaz, construída sem a participação do usuário, indivíduo único que interfere na própria existência da informação.

A exemplo da Desintermediação, os que propõem e sustentam a tentativa de uma corrente ou, ao menos, um novo entendimento para a mediação da informação, a Além da Mediação, o fazem buscando amenizar as propostas políticas, econômicas, culturais entre outras, presentes intrinsecamente na mediação da informação. Mais uma vez, a corrente conservadora, hegemônica na Biblioteconomia e na Ciência da Informação, busca, não de maneira explícita, contestar ideias e concepções contrárias ao seu pensar.

\section{Um preâmbulo como conclusão}

Todo preâmbulo inicia um texto, mas, no caso deste artigo ele o termina, considerando que as ideias aqui expostas são apenas o início, são apenas base para discussões, estudos e pesquisas que elas apontam e sugerem.

Um preâmbulo serve de incentivo para que o leitor se interesse pelo conteúdo do texto aberto por ele; um preâmbulo é a síntese, ao mesmo tempo que uma amostra do que virá. Este preâmbulo/conclusão é uma síntese, sim, mas, contraditoriamente, de algo que ainda está por se concretizar; este preâmbulo/conclusão é uma amostra não do que já é, mas, também estranhamente, do que pode vir a ser. Como autor e pesquisador - e utilizando a primeira pessoa do singular - assumo o compromisso de continuar estudando e trabalhando com o tema, mesmo que esteja ele inserido em discussões mais amplas ou que tenha outras denominações.

Cabe uma observação neste final, importante se considerarmos as discussões que surgiram ao longo do texto: a oposição ao conservadorismo não é, 
como recomendaria, se existisse, um dicionário de antônimos da área, o revolucionário. Mesmo o novo na Biblioteconomia e na Ciência da informação é reformista e não revolucionário, ou melhor, muito pouco revolucionário. Muda-se o superficial, o aparente, mas não o essencial. Mesmo esse superficial, mesmo esse aparente, é contestado, tem sua existência constantemente atingida por propostas contrárias, que o ameaçam, que visam impedir que atinja muitos dos que, de alguma forma, acadêmica ou no mercado, estão envolvidos com a Biblioteconomia e a Ciência da Informação.

Depallens (1987), em artigo que retrata a biblioteca antes e depois da Revolução Sandinista, na Nicarágua, dizia que muitas coisas, como a educação, a saúde, moradia entre outras, mudaram após a Revolução, mas a biblioteca permaneceu a mesma. O título de seu artigo: A biblioteconomia precisa de uma revolução cultural.

Revoluções na Biblioteconomia e na Ciência da Informação não são impossíveis, mas muito difíceis. Devem elas tocar e questionar o que se entende estruturado, sedimentado, solidificado. Essa estrutura sustenta as concepções conservadoras, algumas quase fascistas.

As discussões sobre o protagonismo social, visto pelas lentes e olhos da Biblioteconomia e da Ciência da Informação, com a informação e o conhecimento como formas de sua possível concretude, reconduzem para o palco um tema que ficou esquecido desde os tempos da ditadura explícita, passando pelo neoliberalismo, voltado não somente para a economia, e chegando até um recrudescimento do conservadorismo em várias instâncias da sociedade: a resistência.

A resistência deve ser alvo de análise, deve ser mote de ações não só em relação a cultura, economia, educação, política e outros segmentos, mas, e talvez em especial, dentro das próprias áreas da Biblioteconomia e da Ciência da Informação.

\section{Referências}

ALMEIDA JÚNIOR, O. F. Mediação da informação: um conceito atualizado. In. BORTOLIN, S.; SANTOS NETO, J. A.; SILVA, R. J. Mediação oral da informação e da leitura. Londrina: ABECIN, 2015a. p. 9-32.
ALMEIDA JÚNIOR, O. F. Mediação da Informação: dimensões. Nov. de 2015. In. ALMEIDA JÚNIOR, O. F. Infohome [Internet]. Londrina: OFAJ, 2015b. Disponível em: <http://www.ofaj.com.br/colunas_conteudo.php?cod $=939>$.

ALMEIDA JÚNIOR, O. F. Profissional bibliotecário: um pacto com o excludente. In. BAPTISTA, S. G.; MUELLER, S. P. M. Profissional da Informação: o espaço de trabalho. Brasília: Thesaurus, 2004. p. 70-86. (Estudos Avançados em Ciência da Informação, 3).

ARAÚJO, C. A. Á. Arquivologia, Biblioteconomia, Museologia e Ciência da Informação: o diálogo possível. Brasília: Briquet de Lemos/Livros; São Paulo: Associação Brasileira de Profissionais da Informação (ABRAINFO), 2014.

BARRETO, Aldo de Albuquerque. A questão da informação. São Paulo em Perspectiva, São Paulo, v.8, n.4, p.3-8, out./dez. 1994.

BORKO, H. Information Science: what is it? American Documentation, v. 19, n. 1, p. 3-5, jan. 1968.

CELADEC - Comissão Evangélica Latinoamericana de Educação Cristã. Definição e conteúdo da documentação popular. Recife: SEDIPO, 1981. (Material de Trabalho, 1/81).

CHAUÍ, M. Cultura e democracia: o discurso competente e outras falas. 11.ed. rev. e ampl. São Paulo: Cortez, 2006. 367p.

CHAUÍ, M. A ideologia da competência. In. CHAUÍ, M. A ideologia da competência. Belo Horizonte: Autêntica Editora; São Paulo: Editora Fundação Perseu Abramo, 2014. p.53-58. (Escritos de Marilena Chauí, 3).

DEPALLENS, Jacques. La bibliotecologia necesita de una revolución cultural. Revista Interamericana de Bibliotecologia. Medellin, v. 10, n. 1, p. 7-14, ene./jun. 1987.

INSTITUTO Brasileiro de Informação em Ciência e Tecnologia - IBICT. Site oficial, [s.d.]. Sobre o IBICT - Histórico. Disponível em: 〈http://www.ibict.br/sobre-o-ibict/historico-1 >

MÉSZÁROS, I. A educação para além do capital. São Paulo: Boitempo, 2005.

MÉSZÁROS, I. Para além do capital. São Paulo: Boitempo, 2006.

MIELI, S. Os perigos do Google como único filtro da realidade. Brasil de Fato, v. 6, n. 274, p. 2, 29 de maio a 04 de junho 2008 . 
ORTEGA $\quad$ Y GASSET, J. A missão do bibliotecário. Brasília: Briquet de Lemos/Livros, 2006.

PROGRAMA de Pós-graduação em Ciência da Informação. Site oficial. Apresentação. [s.d.]. Disponível em: <http://www.ppgci.ufrj.br/programa/apresentacao.ht $\underline{\mathrm{ml}}>$
SERRAI, A. História da biblioteca como evolução de uma idéia e de um sistema. Revista da Escola de Biblioteconomia da UFMG. Belo Horizonte, v. 4, n. 2, p. 141-61, set. 1975.

SOUZA, J. A tolice da inteligência brasileira: ou como o país se deixa manipular pela elite. São Paulo: LeYa, 2015. 